\title{
In the light of evolution: a reevaluation of conservation in the $C O-F T$ regulon and its role in photoperiodic regulation of flowering time
}

\author{
Evangeline S. Ballerini ${ }^{\dagger}$ and Elena M. Kramer* \\ Department of Organismic and Evolutionary Biology, Harvard University, Cambridge, MA, USA
}

\section{Edited by:}

Andrew Groover, United States

Forest Service, USA

Reviewed by:

Richard Macknight, University of Otago, New Zealand

Franziska Katharina Turck, Max Planck

Society, Germany

*Correspondence:

Elena M. Kramer, Department of

Organismic and Evolutionary Biology, Harvard University, 16 Divinity

Avenue, Cambridge, MA 02138, USA. e-mail: ekramer@oeb.harvard.edu

\section{${ }^{\dagger}$ Present address:}

Evangeline S. Ballerini, Department of Genetics, University of Georgia, Athens, GA, USA.
In order to maximize reproductive success, plants have evolved different strategies to control the critical developmental shift marked by the transition to flowering. As plants have adapted to diverse environments across the globe, these strategies have evolved to recognize and respond to local seasonal cues through the induction of specific downstream genetic pathways, thereby ensuring that the floral transition occurs in favorable conditions. Determining the genetic factors involved in controlling the floral transition in many species is key to understanding how this trait has evolved. Striking genetic discoveries in Arabidopsis thaliana (Arabidopsis) and Oryza sativa (rice) revealed that similar genes in both species control flowering in response to photoperiod, suggesting that this genetic module could be conserved between distantly related angiosperms. However, as we have gained a better understanding of the complex evolution of these genes and their functions in other species, another possibility must be considered: that the genetic module controlling flowering in response to photoperiod is the result of convergence rather than conservation. In this review, we show that while data clearly support a central role of FLOWERING LOCUS $T(F T)$ homologs in floral promotion across a diverse group of angiosperms, there is little evidence for a conserved role of CONSTANS $(C O)$ homologs in the regulation of these loci. In addition, although there is an element of conserved function for $F T$ homologs, even this component has surprising complexity in its regulation and evolution.

\section{Keywords: flowering time, CONSTANS, FLOWERING LOCUS T, photoperiod}

\section{INTRODUCTION}

Because plants are largely sessile organisms that have little ability to select their environment, controlling the timing of life history transitions so that they occur in the most desirable environmental conditions is critical to survival and fecundity. The timing of flowering, which marks the transition from vegetative to reproductive growth, is a complex trait that has evolved to respond to many cues, both environmental and developmental. In terms of environmental adaptation, we see that plants adapted to a temperate environment, where temperature and day length vary substantially throughout the year, may respond strongly to cues such as day length or the duration of cold exposure while those adapted to tropical regions may respond to influences by other environmental factors such as water availability. Thus, genetic mechanisms that allow plants to sense these different environments and act with developmentally appropriate responses can provide tremendous survival and reproductive advantages.

From an evolutionary perspective, understanding the genetic basis of flowering time in plants with variable growth habits will provide insight into the processes of adaptation. How have genetic regulatory pathways evolved across the angiosperms, from herbaceous annual weeds to giant perennial trees, from alpine wildflowers to tropical grasses? Which genetic elements are conserved and which vary? Have similar phenological responses evolved multiple times using homologous genes and pathways or have novel genes and pathways been recruited to perform similar tasks? One of the best understood environmental inputs from a genetic perspective is the role of photoperiod in controlling flowering time, which has been most extensively studied in the long day flowering core eudicot Arabidopsis and in the short day flowering monocot rice. These lineages diverged $\sim 130-150$ million years ago and the species evolved in quite different geographic regions (Chaw et al., 2004; Magallón and Sanderson, 2005) - Arabidopsis in Old World temperate regions with considerable fluctuation in day length and temperature, and rice in equatorial regions that experience more stable temperature and day length regimes (Vaughan et al., 2003; Koch and Kiefer, 2006). Not surprisingly, these taxa have evolved different flowering phenologies, with Arabidopsis flowering in response to long days and often having a vernalization requirement while the major inductive signal in rice is short days without a requirement for vernalization.

Early genetic analyses of flowering time mutants in Arabidopsis revealed a regulatory pathway controlling photoperiod response consisting of the genes GIGANTEA (GI), CONSTANS (CO), and FLOWERING LOCUS $T(F T)$. This pathway integrates signals from the circadian clock and light cues (via phytochromes and cryptochromes) to initiate flowering in long days (Hayama and Coupland, 2004; Putterill et al., 2004). Work in rice subsequently showed that genes with homology to GI, CO, and FT - Oryza sativa GIGANTEA (OsGI), Heading date 1 (Hd1), and Heading 
date $3 a(H d 3 a)$, respectively - were required for flowering under promotive short days in rice (Hayama and Coupland, 2004; Putterill et al., 2004; Izawa, 2007). Although details of how these homologous genes generate a similar response (flowering) under opposing conditions (long vs. short days) remain unknown, the similarities between these distantly related species has led to the conclusion that these genes function in a conserved genetic pathway (Hayama et al., 2003; Hayama and Coupland, 2004; Izawa, 2007; Turck et al., 2008; Valverde, 2011), and has made their homologs prime candidates for studying photoperiod response in many taxa (Martinez-Garcia et al., 2002; Kim et al., 2003; Hecht et al., 2005; Bohlenius et al., 2006; Chia et al., 2008). As we will review here, the resulting body of data confirms that FT homologs are critical to floral promotion in many taxa but the transcriptional and post-translational factors regulating these loci vary considerably in response to upstream environmental and endogenous signals. The functions of $C O$ homologs are less clear, and despite many studies aiming to show conservation of the CO-FT regulon, there is little solid evidence that the photoperiod-dependent regulation of FT homologs by $C O$ homologs is a major pathway in diverse angiosperms, necessitating a reevaluation of the strict conservation model.

\section{GENE LINEAGE EVOLUTION}

The starting place for any broad consideration of functional evolution is obtaining the best possible picture of the evolution of the genes themselves. In this regard, there are three key areas for consideration: (1) performing as rigorous a phylogenetic analysis as possible, (2) correct assessment of orthology vs. paralogy (including the correct use of those terms), and (3) producing a rigorous ancestral state character reconstruction as applied to gene function. As to point 1, an entire field of evolutionary biology is devoted to the science of phylogenetic reconstruction and ancestral character state reconstruction (Hillis et al., 1996; Page, 1998; Felsenstein, 2003) and, while we do not intend to provide an in depth review of these techniques here, it is important to note that methods such as parsimony and likelihood are preferable to the neighbor-joining approach. Furthermore, with the plethora of gene sequence information available through NCBI and EMBL, broad taxonomic sampling can be used to provide a better evolutionary context and, often, improve resolution. Another relevant consideration is the use of nucleotide sequences vs. amino acids. No simple rule applies in this decision but aspects to weigh include the length of the genes (e.g., shorter genes may be better represented by nucleotides), the breadth of the phylogenetic sampling (with especially ancient sampling, nucleotides are more likely to be saturated) and degree of conservation (e.g., nucleotides may provide more resolution for highly conserved genes). In practice, testing both nucleotide and amino acid datasets is often necessary. Even with all these tools, it may be impossible to get fully resolved trees even when using rigorous analytic techniques, but such a result itself provides important information about uncertainty.

Starting with a well-constructed tree helps avoid another common error - misuse of terms regarding gene homology. In particular, the term ortholog has a very strict definition and should only be applied to a set of genes when their common descent has been confirmed via phylogenetic analysis (Figure 1; Theissen, 2002) and/or when syntenic relationships are clear. It is also
Tracking the evolutionary history of a hypothetical gene family, GENE (GN)

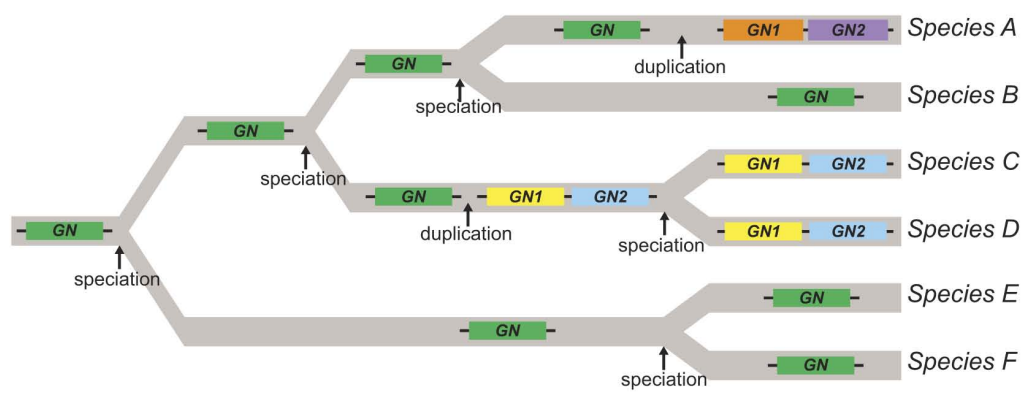

Gene tree of GN homologs

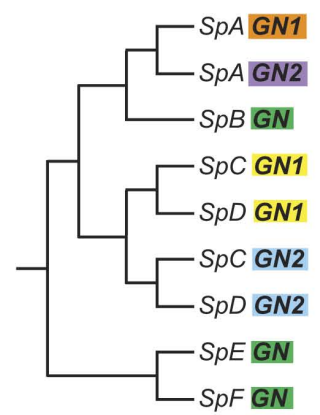

Following the practice seen in scientific literature, gene names are abbreviated such that GENE1 from Species A is represented by SpA GN1

Gene Relationship Vocabulary

These terms are dependent on evolutionary relationships only and are not determined by function which can change over time Orthologs - arise from speciation Paralogs - arise from duplication Homologs - all of these genes could be termed homologs, events events

SpB GN, SpE GN, and SpF GN SpA GN1 and SpA GN2

SpC GN1 and SpD GN1

SpC GN2 and SpD GN2 but the general term is conveniently used in cases with one-to-many and many-to-many relationships that break down simple orthology

eg. $S p F$ GN is equally related to SpC GN1 and SpC GN2, they are homologs
FIGURE 1 | Understanding how speciation and duplication events affect gene orthology, paralogy, and homology. Gene duplication events are commonly recognized as an important mechanism for generating evolutionary novelty (Ohno, 1970). Following a duplication event, a gene pair may diverge in function, with one paralog evolving a new function (neofunctionalization), or with paralogs dividing the function of the ancestral gene between them (subfunctionalization; Force et al., 1999). These duplication events break down gene orthology, however, complicating the relationships between genes. It is critical to understand the evolutionary history of genes in order to understand how their function has evolved through time, especially when comparing function of gene homologs generated via multiple duplication events in which the processes of neo and/or subfunctionalization may have occurred. 
critical to note that even when properly established, orthology does not necessarily imply functional similarity and, reciprocally, functional similarity is in no way a criterion for orthology (Theissen, 2005). Finally, conclusions about the conservation of gene function essentially involve the reconstruction of ancestral character states, which ideally requires a well-constructed phylogenetic hypothesis and broad character state (phenotype, gene function, etc.) sampling (Swofford and Maddison, 1992; Cunningham et al., 1998). The critical question is whether multiple organisms exhibit the same character state due to inheritance from a common ancestor (conservation) or, alternatively, because evolution has led to the independent derivation of that character state, often the result of similar selective forces (convergence). For instance, the phylogenetic position of a CO-like gene in the green alga Chlamydomonas has been misinterpreted to suggest a close evolutionary and functional relationship with the angiosperm loci $\mathrm{CO}$ and $\mathrm{Hd} 1$ (Serrano et al., 2009). In fact, the algal sequence is as closely related to $C O$ and $H d 1$ (type Ia CO-like genes, discussed in further detail below) as it is to another group of $\mathrm{CO}$-like genes that controls light signaling (type Ib CO-like genes). Furthermore, the reconstruction of ancestral function in the $C O$ type I clade is completely equivocal. Thus, the first step in any comparative analysis of functional evolution must start with accurately interpreted phylogenetic analyses and incorporate as much data as possible on gene function across diverse taxa.

\section{THE $\boldsymbol{F T}$-LIKE GENE LINEAGE}

FLOWERING LOCUS $T$ is a member of a family of phosphatidylethanolamine-binding proteins (PEBPs), which were first discovered in mammals but have now been identified in all kingdoms (Granovsky and Rosner, 2008). In plants, PEBP genes have been shown to play important roles in flowering time and inflorescence architecture, as well as a growing list of other developmental processes (see below). There are three major clades of PEBP genes in plants: the FT-like, CEN/TFL-like, and MFT-like clades. The function of $M F T$-like genes, likely the earliest diverging clade, is the least well understood of these gene families but they have been implicated in seed development and germination (Hedman et al., 2009; Nakamura et al., 2011). In contrast to the floral promotion function of homologs from the FT-like clade (Kardailsky et al., 1999; Kobayashi et al., 1999), several members of the CEN/TFL clade have been shown to delay flowering and maintain indeterminacy in inflorescence meristems, including CEN from Antirrhinum and TFL from Arabidopsis (Bradley et al., 1996, 1997). Here we use nucleotide alignments and a maximum likelihood optimality criterion as implemented by the randomized accelerated maximum likelihood (RAxML) program (Stamatakis, 2006) via the publically available CIPRES (Cyberinfrastructure for Phylogenetic Research, www.phylo.org) cluster to explore phylogenetic relationships of plant PEBP genes from a wide variety of angiosperms and some non-angiosperms. Nucleotides were used because the FT genes are both relatively short (752 nucleotide characters in the dataset) and highly conserved, therefore, better resolution could be obtained with nucleotides rather than amino acids. We recovered the three expected main clades with high bootstrap support, however, the relationship of these main clades to one another is poorly supported (Figure 2 and Figure A1

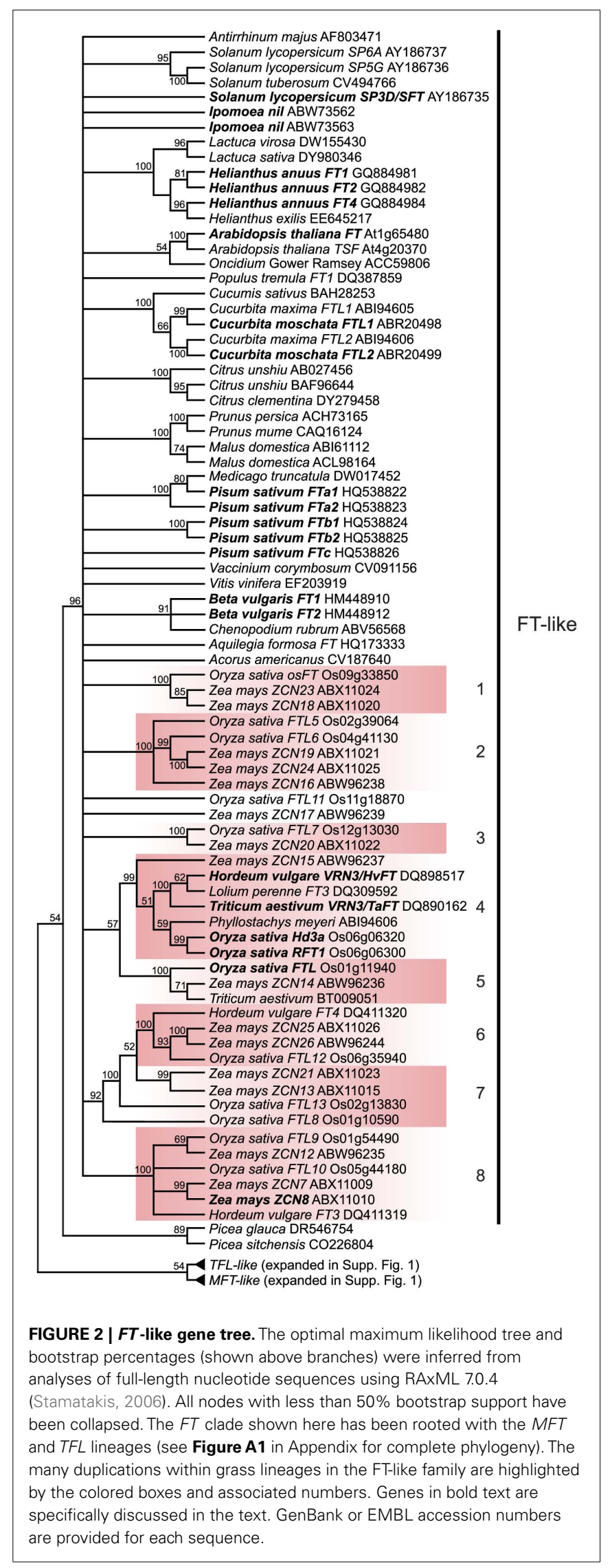


in Appendix). Due to the short length and high sequence conservation in these genes, there is less support for internal nodes and relationships with less than $50 \%$ bootstrap support have been collapsed. While amino acid conservation across the FT-, TFL-, and MFT-like clades is high, variation at a few critical amino acid positions is synapomorphic for each family. In fact, Hanzawa et al. (2005) have shown that reciprocally switching one amino acid between FT and TFL (Y85H and H88Y) is enough to interconvert the floral promotion and floral-repression functions of these proteins. Consistent with this, all FT-like genes have a conserved Tyrosine (Y) at Arabidopsis position 85, while TFL-like genes have a conserved Histidine $(\mathrm{H})$ at this position and MFT-like genes have a Tryptophan (W).

Of key importance within the FT-like lineage are the highly supported monophyletic clades that indicate extensive duplication within the grasses (Figure 2). The current phylogeny supports a minimum of eight grass-specific duplication events prior to the split of the BEP and PACCAD clades (containing rice and maize, respectively), leading to the presence of 13 rice $F T$ genes and 16 maize FT genes. These are much higher than the copy numbers for dicots, which are four or five at most in the taxa examined thus far. There is little information about the functions of many of these loci aside from $\mathrm{Hd} 3 \mathrm{a}$ and $\mathrm{RFT} 1$ in rice and, based on diversification of their expression patterns (Danilevskaya et al., 2008), their functions may be similarly diverse.

\section{THE CO-LIKE LINEAGE}

CONSTANS belongs to a family of zinc finger transcription factors unique to plants. Genes in this family are marked by the presence of either one or two zinc finger B-box domains in the $\mathrm{N}$-terminus of the protein and a C-terminal CCT domain, so named for its presence in three early cloned Arabidopsis genes (CO, CO-like, and TOC1; Putterill et al., 1995; Griffiths et al., 2003). The CCT domain is not unique to CO-like genes, however, as 45 genes in Arabidopsis, including $17 \mathrm{CO}$-like genes, contain a CCT domain (Wenkel et al., 2006; Figure 3). These diverse loci are known to function in a variety of physiological responses across plants, including photoperiodic response, light signaling, the regulation of circadian rhythms, and vernalization response (Figure 3; Putterill et al., 1995; Strayer et al., 2000; Yan et al., 2004; Cheng and Wang, 2005; Nakamichi et al., 2005; Datta et al., 2006; Xue et al., 2008).

Genomic studies in Arabidopsis, rice, and barley have revealed extensive duplication events of genes containing at least one B-box and one CCT domain, with $\sim 17$ such genes present in Arabidopsis, $\sim 16$ present in rice, and $\sim 9$ present in barley (Griffiths et al., 2003). These loci are broken into three major groups: type I CO-like genes containing two B-box domains; type II CO-like genes, with only one B-box domain; and type III CO-like genes, with one full B-box and one degraded B-box (Figure 3; Griffiths et al., 2003; Serrano et al., 2009). We focused on only the type I CO-like genes, as this is the group to which the $C O$ and $H d 1$ flowering time loci belong. In contrast to recent studies focusing on Arabidopsis B-box genes sensu lato (Khanna et al., 2009), we are primarily concerned with B-box loci that also contain CCT domains across a wide breadth of plants, so we have used the terminology of Griffiths et al. (2003). We constructed several phylogenies using a maximum likelihood optimality criterion as implemented by RAxML (Stamatakis, 2006) in analyses of full-length amino acid alignments, collapsing all nodes with less than $50 \%$ bootstrap support. In this case, the use of amino acid sequences was permitted by the longer length (588 amino acid characters) and lower sequence conservation of these homologs. This analysis reveals two major clades of type I genes, designated type Ia and type Ib (Figure A2 in Appendix) in which both clades contain both eudicots and monocots, with high support for monophyletic grouping of the monocots. The type Ia group contains both Arabidopsis $C O$ and rice $H d 1$, the known flowering time loci (Figure 4).

\section{Basic types of CCT domain genes}

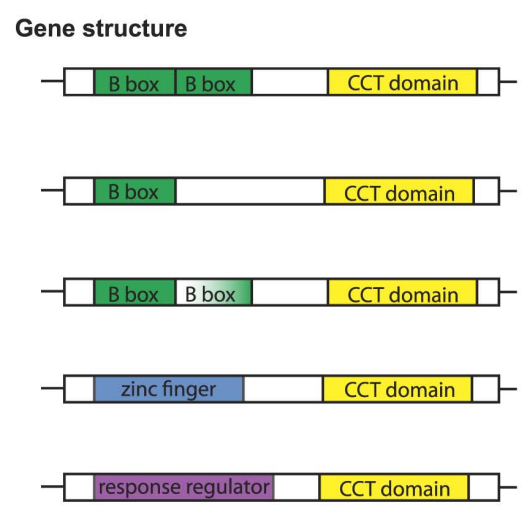

FIGURE 3 | Basic types of CCT domain containing genes and their known functions. Several groups of plant genes contain CCT domains. Groups I-IV have been described in Griffiths et al. (2003). All CCT domain genes described have a CCT domain in the $3^{\prime}$ portion of the gene but vary in the 5' region. Group I genes have two 5' B-box zinc finger domains. Group II genes have only one 5' B-box zinc finger domain. Group III genes have two $5^{\prime}$

\begin{tabular}{|c|c|}
\hline Type & Known functions \\
\hline $\begin{array}{l}\text { Group I CO-like: CO, } \\
\text { AtCOL1-AtCOL5, Hd1, } \\
\text { PsCOLa }\end{array}$ & $\begin{array}{l}\text { photoperiod response, light } \\
\text { signalling }\end{array}$ \\
\hline $\begin{array}{l}\text { Group II CO-like: AtCOL6- } \\
\text { AtCOL8, AtCOL16, OsJ-OsL }\end{array}$ & photoperiod response \\
\hline $\begin{array}{l}\text { Group III CO-like: AtCOL9- } \\
\text { AtCOL15, OsM, OsN }\end{array}$ & photoperiod response \\
\hline $\begin{array}{l}\text { Group IV CO-like: ZCCT } \\
\text { (VRN2), Ghd7(Osl), HvCO9, } \\
\text { OsH }\end{array}$ & photoperiod response \\
\hline $\begin{array}{l}\text { Pseudo Response } \\
\text { Regulators: TOC1, APRRs, } \\
P P D-H 1\end{array}$ & $\begin{array}{l}\text { central oscillator, circadian } \\
\text { clock components, photoperiod } \\
\text { response }\end{array}$ \\
\hline $\begin{array}{l}\text { B-box zinc finger doma } \\
\text { Group IV genes are the } \\
\text { finger somewhat repre } \\
\text { regulators have a } 5^{\prime} \text { res } \\
\text { example loci are listed } \\
\text { references). }\end{array}$ & $\begin{array}{l}\text { ins, however the second domain is partially degraded. } \\
\text { least well described and have a less conserved } 5^{\prime} \text { zinc } \\
\text { senting a } \mathrm{C}_{2} \mathrm{H}_{2} \text { zinc finger. The pseudo response } \\
\text { ponse regulator domain. For each type, characterized } \\
\text { along with their known functions (see text for }\end{array}$ \\
\hline
\end{tabular}




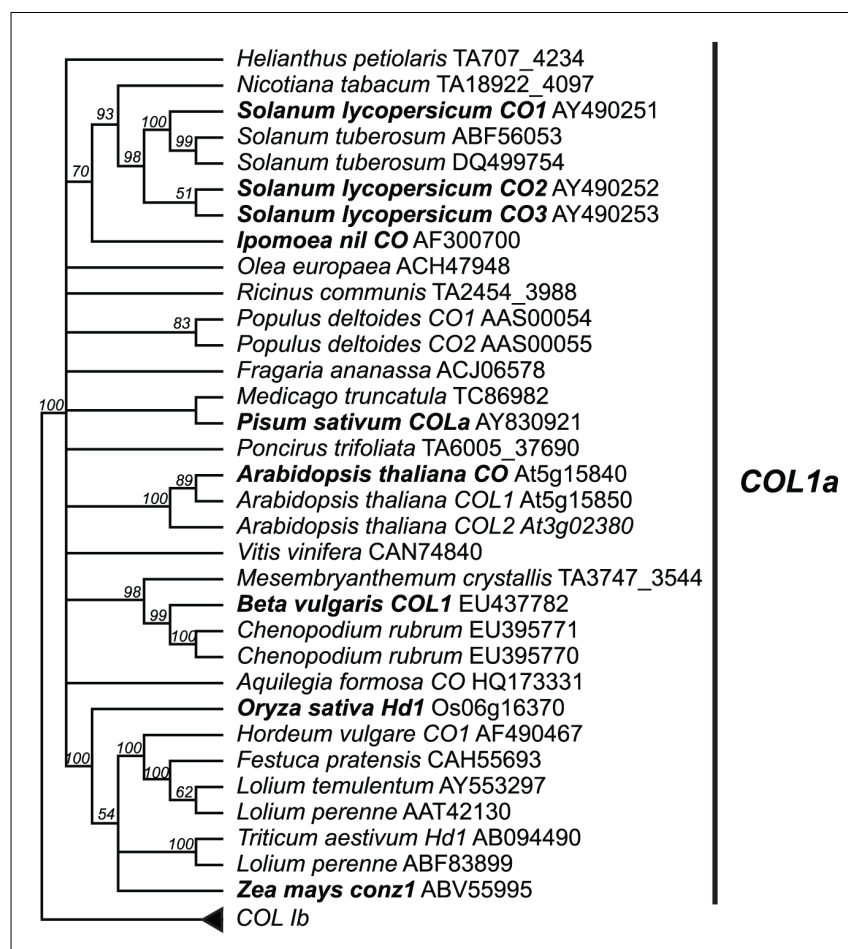

FIGURE 4 |Type la $\mathbf{C O}$-like gene tree. The optimal maximum likelihood tree and bootstrap percentages (shown above branches) were inferred from analyses of full-length amino acid sequences using RAxML 7.0.4 (Stamatakis, 2006) with the JTT amino acid substitution matrix. All nodes with less than $50 \%$ bootstrap support have been collapsed. The type la clade of CO-like genes shown here has been rooted with the type Ib clade (see Figure $\mathbf{A 2}$ in Appendix for complete phylogeny). Genes in bold text are specifically discussed in the text. GenBank or EMBL accession numbers are provided for each sequence.

\section{MAJOR MODELS: THE FUNCTION OF FT AND CO HOMOLOGS IN ARABIDOPSIS AND GRASSES \\ ARABIDOPSIS: ESTABLISHING THE MODEL}

Early grafting experiments led to the proposition that a floral promoting factor, termed florigen, moves from plant leaves to apices to induce flowering (Chailakhyan, 1937). In 2007, several experiments provided strong evidence that the protein product of the FT locus, already known to promote flowering in response to both photoperiod and vernalization, functions as the major mobile florigen component in Arabidopsis (Corbesier et al., 2007; Jaeger and Wigge, 2007). Consistent with this, flowering time correlates with the level of $F T$ mRNA, which increases gradually as plants mature and reaches higher levels in LD (Kardailsky et al., 1999; Kobayashi et al., 1999). CO is a direct upstream regulator of FT that imparts a long day photoperiod response (Putterill et al., 1995; Kardailsky et al., 1999; Kobayashi et al., 1999). The expression of $C O$ mRNA is controlled by the circadian clock such that $C O$ has a diurnal expression pattern with peak levels occurring $\sim 16 \mathrm{~h}$ post dawn (Suarez-Lopez et al., 2001). Studies have shown that the CO protein is only stable during daylight and that in darkness the protein gets targeted for proteasomal degradation (Valverde et al., 2004). Thus, only under LD conditions do levels of CO mRNA reach significantly high levels during daylight to result in amounts of stable CO protein sufficient to upregulate FT (Suarez-Lopez et al., 2001; Valverde et al., 2004). Additional studies showed that $F T$ is also downstream of the vernalization gene FLOWERING LOCUS C (FLC) and is important for integrating signals between the photoperiod and vernalization pathways (Michaels et al., 2005; see Kim et al., 2009 for an extensive review of the vernalization pathway). A recent paralog of FT, TWIN SISTER OF FT (TSF), is largely redundant with $F T$, although TSF appears to have a role independent of $F T$ in promoting eventual floral induction in $\mathrm{SD}$ (Yamaguchi et al., 2005).

\section{RICE AND OTHER GRASSES: DIVERSIFICATION IN FT COPY NUMBER AND INVOLVEMENT OF NEW CCT DOMAIN GENES}

Outside of Arabidopsis, the monocot grasses are the best understood models for the genetic control of flowering (Figure 5). As shown in the phylogenetic analysis (Figure 2), the FT-like genes have undergone extensive duplication in this group. Although little is known about the function of most of these homologs, which are all equally related to Arabidopsis FT and TSF, the rice locus $H d 3 a$ has been shown to be largely responsible for the promotion of flowering under short day inductive conditions, although does not appear to have a strong role in the eventual flowering of plants grown in long days (Kojima et al., 2002). As with Arabidopsis FT, Hd3a was also shown to function as a mobile protein, moving from leaves to the meristem (Tamaki et al., 2007). There is further evidence for a role in flowering time for two other rice $F T$ homologs: RFT 1, a recent paralog of $H d 3 a$, and $F T L$, a member of a related but separate lineage (clade 5 in Figure 2). RFT1 knockdown alone has a negligible effect on flowering time but RFT 1 $H d 3 a$ double knockdowns do not flower even after 300 days, suggesting that RFT1 may function as a back-up to $H d 3 a$, particularly in long days (Komiya et al., 2008). Less is known about FTL, but overexpression promotes the premature transition of the SAM to a terminal bud (Izawa et al., 2002).

In terms of upstream regulation of the FT homologs, there is evidence that the $\mathrm{CO}$ homolog, $\mathrm{Hd} 1$, controls aspects of $\mathrm{Hd} 3 \mathrm{a}$ expression, however, experiments suggest that $H d 1$ plays both a promotive role in SD and a repressive role in $\mathrm{LD}$, a very different picture from CO-FT in Arabidopsis (Yano et al., 2000; Izawa et al., 2002). Furthermore, the mechanisms by which $H d 1$ function is regulated appear to differ. In non-inductive $\mathrm{LD}, H d 1$ levels begin to rise while it is still light, similar to what is seen during inductive periods with Arabidopsis CO, but in SD when $H d 1$ is actually presumed to activate $H d 3 a$, expression levels remain low throughout the day (Kojima et al., 2002). A key component to understanding how Hd1 works will be protein stability studies, which may provide insight into the capacity of $\mathrm{Hd} 1$ to promote or suppress flowering in $\mathrm{SD}$ and $\mathrm{LD}$, respectively.

In addition to complexities surrounding how $H d 1$ regulates $H d 3 a$, many other rice loci have been identified as playing a role in photoperiod regulation of $\mathrm{Hd} 3 \mathrm{a}$. Ehd 1, a B-type response regulator with no clear homolog in Arabidopsis, induces flowering via $H d 3 a$ in SD independently of $H d 1$ (Doi et al., 2004) and interestingly, a different CCT domain containing gene that contains a zinc finger but no B-boxes, Grain number, plant height, and heading date 7 (Ghd7, Figure 3), is responsible for preventing the expression of Ehd 1 and Hd3a in LD (Xue et al., 2008). The 


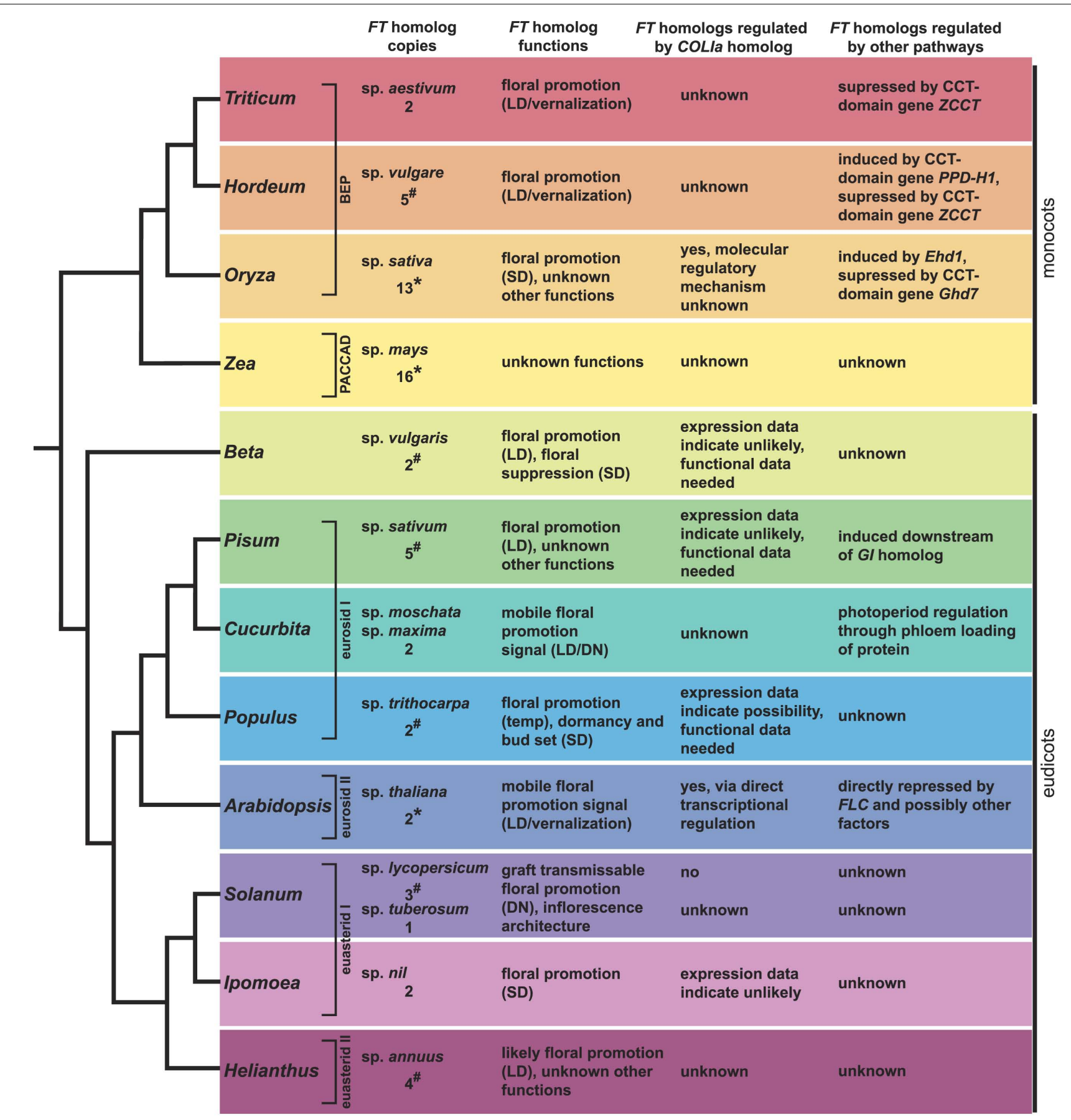

\section{FIGURE 5 | Summary of FT and COLla homolog data from}

across angiosperms. Major angiosperm model systems discussed in the text with information on their number of FT homologs, the functions of these loci (when known), and information on their regulation. See text for relevant references. Under "FT homolog copies," *indicates that the copy number is based on genome sequencing, \#indicates that the copy number is based on EST or BAC library screening, and unlabelled values come from targeted gene cloning. All of these numbers should be considered minimum estimates, although the values generated from sequenced genomes are more likely to be correct. importance of the Ehd 1 pathway in the environmental control of flowering has been highlighted by a fascinating study of a diverse set of rice cultivars. Takahashi et al. (2009) examined gene activity of six flowering time loci in 64 cultivars of rice from across the Asian continent that varied in heading date from 45 to 153 days when grown in the same environment. As might be expected, they found that $\mathrm{Hd} 3 \mathrm{a}$ expression levels are strongly correlated with flowering time but, surprisingly, they also found that at least half of the $H d 1$ alleles (also representing the most common alleles) produce non-functional proteins. Although there is 
moderate correlation of $H d 3 a$ expression with the functionality of the $H d 1$ allele, it is also clear that other loci, including Ehd1, must play a major role in regulating $H d 3 a$. This raises questions as to how broadly applicable the $H d 1 \rightarrow H d 3$ pathway is across rice, let alone the grasses, and re-emphasizes the importance of considering natural variation even in broader comparative studies.

In the temperate grass species wheat (Triticum aestivum, Poaceae) and barley (Hordeum vulgare, Poaceae), the flowering time locus VRN3 maps to syntenous FT homologs in each species, TaFT and $H v F T$, respectively, and these loci promote flowering downstream of both photoperiod and vernalization inputs (Yan et al., 2006). Several wheat and barley CO homologs have been identified through sequence similarity, but there is no functional information thus far to show that they are involved in flowering (Nemoto et al., 2003; Turner et al., 2005). Instead, studies in barley have shown that two other CCT domain containing genes, VRN2 and PHOTOPERIOD-H1 (PPD-H1; Figure 3), affect flowering time in a photoperiod-dependent manner, in part by regulating the expression of $H v F T$. The VRN2 locus is composed of two recently duplicated zinc finger CCT domain containing genes (ZCCT genes) in which the $\mathrm{C} 2 \mathrm{H} 2$ zinc finger domain has sequence similarity with $G h d 7$ in rice. Like Ghd7, the ZCCT genes repress $H v F T$ expression in LD, but the process of vernalization in barley suppresses expression of the ZCCT genes such that HvFT can be expressed in LD following vernalization (Trevaskis et al., 2006, 2007). $P P D-H 1$, a pseudo response regulator containing both a pseudo receiver and a CCT domain, appears to promote flowering in LD via induction of $H v F T$ in the absence of ZCCT expression (Turner et al., 2005; Hemming et al., 2008). While the ZCCT and $P P D-H 1$ genes have a definite effect on the levels of $H v F T$ and flowering time, it is unclear if either of the two $\mathrm{HvCO}$ genes play a role in flowering in barley. The circadian expression pattern of $\mathrm{HvCO} 1$ is slightly altered in $p p d-H 1$ and $\mathrm{HvCO} 2$ shows a general decrease in expression, but the circadian pattern of these genes is not highly correlated with wild type $P P D-H 1$ expression and both genes maintain relatively high levels of expression during daylight in the mutant (Turner et al., 2005). HvCO1 and $\mathrm{HvCO} 2$ mutants or RNAi knockdown lines would be necessary to determine if these genes are involved in the upstream regulation of $H v F T$ and flowering in barley. Screening of a $H$. vulgare EST dataset revealed that there are at least four additional FT homologs (HvFT2-5), however their functions remain unknown (Faure et al., 2007).

A genome-wide survey of maize reveals the presence of at least 15 FT homologs, termed Zea mays CENTRORADIALIS, or ZCN genes (Danilevskaya et al., 2008). Functional data is lacking for most of these genes, but expression analyses show that these genes have evolved diverse expression profiles in different maize tissues. Interestingly, ZCN 15, the homolog most closely related to $\mathrm{Hd} 3 \mathrm{a}$ and RFT 1 in rice and TaFT and HvFT in wheat and barley, respectively (Figure 2, clade 4), is detected primarily in floral tissues following fertilization, suggesting that this homolog does not play a role in floral promotion (Danilevskaya et al., 2008). On the other hand, $Z C N 8, Z C N 12$, and $Z C N 26$ are strongly expressed in leaf blades, indicating that one of these genes may instead be functioning to promote flowering similar to the rice, wheat, and barley FT homologs mentioned above (Danilevskaya et al., 2008). It was recently shown that $Z C N 8$ exhibits diurnal expression patterns in a SD flowering maize variety, consistent with a role in floral promotion, and when ectopically expressed in the shoot apex, ZCN8 induces early flowering (Meng et al., 2011). It is thus possible that different clades of FT homologs control floral promotion function in the two major grass clades - the primarily temperate BEP grasses (Bambusoideae, Ehrhartoideae, Pooideae; including Oryza, Hordeum, and Triticum) and the primarily warm climate PACCAD grasses (Panicoideae, Arundinoideae, Chloridoideae, Centothecoideae, Aristidoideae, Danthonioideae; including Zea). While the maize $C O$ homolog, conz1, does show circadian regulation, it is unknown if it regulates any of the many maize FT homologs (Miller et al., 2008).

\section{EMERGING DICOT MODELS: EVIDENCE FOR DIVERSITY IN FT HOMOLOG FUNCTION AND REGULATION}

Our understanding of FT homolog function in dicots outside the Brassicaceae is growing and now includes Populus, Ipomoea, Solanum, Cucurbita, Pisum, Helianthus, and Beta (Figure 5). As new environmental types and growth forms are sampled, it is becoming clear that the variation in flowering time genetics may be more interesting than the conservation.

\section{POPULUS: FLOWERING IN LONG-LIVED PERENNIALS}

While most work on flowering and the CO-FT regulon has centered on annual herbaceous taxa, a pair of studies have examined the recently derived paralogs PtFT1 and PtFT2, FT homologs in the long-lived tree Populus trichocarpa (Salicaceae; Bohlenius et al., 2006; Hsu et al., 2011). Several lines of evidence indicate that PtFT1 promotes floral initiation. Populus usually spend 820 years in the juvenile phase before the annual production of inflorescences begins, however, overexpression of PtFT 1 results in the production of flower-like structures after just 4-weeks (Bohlenius et al., 2006). Consistent with this role in floral induction, expression of PtFT1 is specifically promoted by cold treatment in reproductively mature trees, corresponding to the winter development of inflorescences (Hsu et al., 2011). In contrast, the PtFT2 paralog is only expressed under warm, long day conditions (Hsu et al., 2011). This photoperiod-responsive expression of PtFT2 appears to mediate the developmental decision to maintain vegetative bud growth or undergo growth cessation and dormancy in preparation for over-wintering. This role was uncovered in heatshock inducible PtFT2 plants where normally inductive SDs fail to initiate bud set and growth cessation, instead continuing to grow vegetatively (Hsu et al., 2011). The significance of this function is reflected in studies of natural European aspen clones, which exhibit a latitudinal cline such that the day length required to promote PtFT 1/2 expression shifts between populations (note, Bohlenius et al. (2006) did not distinguish between expression of PtFT1 and 2 but the subsequent study of Hsu et al. (2011) indicates that PtFT2 is the specific regulator of bud dormancy). Plants from the northernmost latitude experience a decline in $P t F T 1 / 2$ expression and corresponding growth cessation at much longer day lengths (effectively earlier in the year) than those from progressively more southern latitudes. Interestingly, the paralog specifically involved with flowering, $P t F T 1$, does not show diurnal expression variation and appears to be strictly controlled by temperature (Hsu et al., 2011). Rather, it is the vegetative growth/dormancy paralog, 
PtFT2, that is strongly regulated by photoperiod. The latitudinal study provided some evidence that the Populus CO homolog PtCO2 controls PtFT2 since diurnal expression peaks of PtCO2 appear to shift between populations in a manner that tracks the shifts of dormancy response (Bohlenius et al., 2006). It is interesting to note, however that although the peak in $\mathrm{PtCO} 2$ expression occurs earlier in plants from southern populations, the overall expression levels of $\mathrm{PtCO} 2$ are higher in northern populations such that even the lowest levels of PtCO2 expression at all circadian points in northern populations appear higher than the peak expression of the gene in southern populations. Thus, in northern populations, the relatively high level of PtCO2 expression at all circadian points is not consistent with the Arabidopsis protein stability model, as high base levels of PtCO2 would occur during daylight even in short days. Reduced PtFTL1/2 expression in PtCO2 RNAi knockdown lines provides some functional evidence that PtCO2 may regulate PtFT2 (Bohlenius et al., 2006), but examining $\mathrm{PtCO} 2$ protein stability in different light conditions would be key to understanding when the protein is active. Regardless, in the context of flowering, it would appear that PtFT1 regulation is not photoperiod sensitive as previously assumed (Bohlenius et al., 2006), but only regulated by vernalization (Hsu et al., 2011).

\section{IPOMOEA: SHORT DAYS, LONG NIGHTS}

Morning-glory (Ipomoea nil, formerly Pharbitis nil) has long served as a model for studying SD flowering, although night length is really the critical factor promoting flowering (Imamura, 1967). At least two FT homologs, PnFT1 and PnFT2, and one CO homolog, PnCO, have been identified in Ipomoea (Liu et al., 2001; Hayama et al., 2007). Several lines of evidence indicate a role in floral promotion for the FT homologs. Diurnal expression of these genes, which rises gradually through the night and peaks in the morning, is induced only in floral promoting SD conditions and is disrupted by night breaks that inhibit flowering (Hayama et al., 2007). In addition, overexpression of $P n F T 1$ dramatically speeds flowering in LD (Hayama et al., 2007). While circadian expression peaks of $\mathrm{PnCO}$ and the PnFTs coincide in SD, expression of these genes moves out of phase as dark-to-light and light-todark transitions are experimentally modified, indicating that there is no direct regulatory action of $\mathrm{PnCO}$ on either PnFT homolog (Hayama et al., 2007). However, as Hayama et al. (2007) note, the search for $\mathrm{CO}$ homologs in Ipomoea was not exhaustive and there may be other $C O$ homologs that regulate expression of $P n F T$.

\section{SOLANUM: A DAY NEUTRAL LIFESTYLE}

A major question arising from the hypothesis that the CO-FT regulon is conserved in angiosperms is how this regulon would function in day neutral plants. While there is significant evidence that FT homologs promote flowering in day neutral tomato varieties, there is no indication that its regulation is downstream of CO homologs (Ben-Naim et al., 2006). In day neutral tomato (Solanum lycopersicum, Solanaceae), the flowering phenotype is largely dependent on overall plant architecture. Typically, after a juvenile growth period that produces 8-12 leaves, the SAM is terminated by a cymose inflorescence. A new vegetative shoot then begins growing in the axil of the last leaf and this shoot will produce three leaves before terminating in another inflorescence with a new vegetative shoot again initiating in the axil of the last leaf (Lifschitz et al., 2006). This process repeats indefinitely, establishing a sympodial growth habit in which plants essentially make frequent transitions between vegetative and reproductive shoot production. Thus, there are two measures of flowering in tomato, one is the number of leaves on the primary shoot until the first inflorescence and then, subsequently, the number of leaves in each sympodial unit prior to production of another inflorescence in the secondary shoots. Plants mutant for the FT homolog SINGLEFLOWER TRUSS (SFT) are late flowering in regards to both the appearance of the first inflorescence, after 15-20 leaves in the primary shoot, and the subsequent formation of a shoot lacking strict sympodial units with indeterminate vegetative and inflorescence characteristics that produces far more leaves than flowers (Lifschitz et al., 2006). 35S:SFT lines show the opposite phenotype, inducing the formation of the initial inflorescence after only three to five leaves and reducing the number of leaves in sympodial units from 3 to 2 (Lifschitz et al., 2006). The ability of 35S:SFT to rescue the $s f t$ phenotype is graft transmissible and SFT RNA is not detected in the sft stocks, strongly suggesting that the SFT protein is moving from the scion to the stock (Lifschitz et al., 2006).

Interestingly, SELF PRUNING (SP), a tomato TFL homolog, has the opposite effect on flowering, as plants homozygous for the $s p$ mutant produce fewer and fewer vegetative nodes between each inflorescence until eventually two inflorescences in a row are formed, effectively terminating the meristem (Pnueli et al., 1998; Shalit et al., 2009). It appears that SFT is important for the initial transition to flowering and a balance between the expression of SFT and SP is largely responsible for controlling a continuous alternation between vegetative and reproductive growth that results in the complex inflorescence structure of tomato (Pnueli et al., 1998; Shalit et al., 2009). In addition, this SFT/SP module influences other aspects of development including leaf architecture, abscission zone formation, and radial expansion of stems (Shalit et al., 2009). The functions of the other two tomato FT homologs (SP6A and SP5G) and the other tomato TFL homolog $(S P 9 D)$ remain largely unexplored. The upstream regulatory mechanisms controlling these genes remain unknown, but they do not appear to be downstream of the tomato $\mathrm{CO}$ homologs TCOL1, TCOL2, or TCOL3. TCOL2 has a frameshift mutation before the CCT domain and while both TCOL1 and TCOL3 show circadian expression patterns, their overexpression has no clear effect on flowering time (Ben-Naim et al., 2006). Interestingly, $\mathrm{CO}$-like genes have been implicated in the regulation of a different photoperiod response, tuberization, in the closely related species potato (Solanum tuberosum; Martinez-Garcia et al., 2002).

\section{CUCURBITA: EVIDENCE FOR POST-TRANSLATIONAL REGULATION}

Convincing evidence that $F T$-like proteins are a mobile florigen capable of responding to day length also comes from work in cucurbits (Cucurbita spp., Cucurbitaceae), however the regulatory mechanism of these homologs is quite different than that of Arabidopsis. In the cucurbits, the FT lineage has undergone an independent duplication resulting in two FT homologs, CucurbitaFTL1 and CucurbitaFTL2. In a variety of Cucurbita moschata that flowers only in SD, scions were induced to flower in LD when grafted to flowering C. maxima stocks, showing that a florigenic 
signal moves from C. maxima to C. moschata to promote flowering (Lin et al., 2007). Surprisingly, the mRNA levels of CmoFTL1 and CmoFTL2 in C. moschata are high in both inductive SD and non-inductive LD (Lin et al., 2007). However, the protein levels of these genes in phloem sap differ greatly between SD and LD with levels of CmoFTL1 nearly $5 \times$ higher in SD and CmoFTL2 nearly $40 \times$ higher in SD (Lin et al., 2007). This indicates that in the cucurbits, phloem-loading of the FT homolog protein may be the important distinction between floral induction in SD vs. LD, and not transcriptional regulation by CO-like genes (Lin et al., 2007).

\section{PISUM, HELIANTHUS, AND BETA: MORE COPIES, MORE VARIATION}

Although loss-of-function is hypothesized as the most common fate of gene duplicates, neofunctionalization, and subfunctionalization can cause paralogous genes to acquire new functions or divide aspects of the ancestral gene's function between them (Force et al., 1999). Complementing the studies in poplar discussed above, recent work in pea (Pisum sativum, Fabaceae), sunflower (Helianthus annuus, Asteraceae), and beet (Beta vulgaris, Amaranthaceae) indicates that duplication events in the FT lineage have led to the diversification in the regulation and function of these genes.

Five PEBP genes belonging to the FT-like lineage have been identified in pea: PsFTa $1, P s F T a 2, P s F T b 1, P s F T b 2$, and PsFTc (Hecht et al., 2011). Although functional data for all five genes has not yet been obtained, expression analyses across various development stages, in different day length conditions (LD vs. SD), in different tissue types (expanded mature leaf vs. apex and very young leaves) and in two mutant backgrounds (late bloomer 1, a GI homolog mutant that delays flowering in $\mathrm{LD}$, and die neutralis, an EARLY FLOWERING four homolog mutant that speeds flowering in SD), indicate that these homologs are differentially regulated and likely have different functions from one another. Mutations in PsFTa1 are responsible for the gigas mutant phenotype, which has delayed flowering in both $\mathrm{LD}$ and $\mathrm{SD}$, providing functional evidence for a role in floral promotion for at least one of these FT homologs (Hecht et al., 2011). Data from grafting experiments between wild type, gigas, late bloomer 1 (late 1 ), and die neutralis (dne) stocks and scions indicates that both PsFTa1 and PsFTb2 are responsible for generating, or may themselves act as, mobile signals signaling flowering downstream of photoperiod input. Based on the expression profiles of PsFTa1 and PsFTb2, PsFTb2 would make the best candidate for the primary $F T$ homolog responsible for the photoperiod response initiating flowering in LD (Hecht et al., 2011). Although good candidates for the upstream regulatory control of these genes remain unknown, PsFTa1 and PsFTb2 are clearly downstream of the GI homolog LATE1, but it is unlikely that regulation of these genes is via the pea CO homolog, PsCOLa, as expression of PSCOLa is unchanged in the late 1 mutant (Hecht et al., 2007).

Similar to pea, multiple FT homologs have been identified in the sunflower, $H$. annuus. Flowering time, an important trait for domestication, differs between the wild and domesticated populations of sunflower, with the wild progenitor flowering faster in SD while the domesticated variety flowers faster in LD. After examining expression patterns, sequence, and heterologous expression of these homologs - HaFT1, HaFT2, HaFT3, HaFT4 - from both the wild progenitor and the domesticated variety, Blackman et al. (2010) drew several conclusions regarding their diversification of expression and function. First, expression studies show that spatial regulation of the paralogs has diverged relative to one another. HaFT2 and HaFT4 are both expressed in the leaves, HaFT1 is expressed in the apex, and HaFT3 does not appear to be expressed. Additionally, changes in cis-regulation of HaFT2 are hypothesized to promote early flowering in $\mathrm{LD}$, while a frameshift mutation in the HaFT 1 copy from the domesticated variety, which falls in the region of a QTL for flowering time, is proposed to regulate the function of HaFT4 in a dominant-negative fashion. Although true functional analyses using mutants and transgenic plants will be necessary to fully understand how these homologs function, these initial studies indicate that there is not a simple one-to-one conservation between the function of these sunflower homologs and Arabidopsis FT.

Beta (beet) is another case in which a duplication event in the FT lineage has lead to diversification in expression and function. There are two FT paralogs present in the genus Beta and elegant studies carried out in the cultivated variety $B$. vulgaris vulgaris indicate that one of the paralogs, $B v F T 2$, acts as a floral promoter in LD following vernalization treatment (Pin et al., 2010). The other paralog, $B v F T 1$, is only expressed in the juvenile phase of development in SD and prior to vernalization. Overexpression studies with $B v F T 1$ indicate it opposes the function of $B v F T 2$ by acting as a floral repressor prior to vernalization and in short days. Although the expression patterns differ, both of these genes show circadian regulatory patterns, indicating that they are downstream of photoperiod or clock elements. It is interesting to note that while constitutive expression of $B v C O L 1$, the closest beet homolog to $C O$ (Chia et al., 2008), can rescue the co-2 mutant phenotype in Arabidopsis, the endogenous expression levels of $B v C O L 1$ differ from that of $C O$ such that $B v C O L 1$ levels are near zero except for the first hour after dawn. Thus, there is no substantial evidence that $B v C O L 1$ is functioning the same way as $\mathrm{CO}$ to induce flowering in $\mathrm{LD}$ in beet.

\section{CONCLUSION}

Although the parallels between the GI-CO-FT and OsGI-Hd1$H d 3 a$ regulons are striking in some ways, it is important to remember that these datasets are drawn from two distantly related taxa. Asserting that this module is conserved between Arabidopsis and rice (e.g., Valverde, 2011) implies that the developmental network of $C O$ homologs regulating FT homologs to control photoperiodic flowering not only evolved prior to the divergence of the monocots and eudicots, but also that it was commonly inherited along the branches leading to these taxa. As studies examining the genetic basis of flowering have expanded, we see now that there is strong evidence that FT homologs have a conserved role in promoting flowering. However, evidence that $\mathrm{CO}$ homologs have regulatory control of these homologs is limited and based primarily on coincidental expression patterns (Figure 5). In this regard, it may be useful to separate the clearly conserved role of some FT homologs as floral promoters from that of CO homologs as potential regulators of $F T$-like genes.

While there is substantial evidence that FT homologs function as mobile signals to promote flowering in families spanning 
deep divergences of the angiosperms, understanding all of the factors that regulate these genes will be critical to understanding how the functions of FT loci in flowering have evolved. Recent studies have revealed diversification of both transcriptional and post-translational regulatory mechanisms, which appear to reflect variation in FT homolog copy number, integration of different environmental signals and, most likely, a degree of developmental system drift (True and Haag, 2001). One emerging theme is the real breadth of the FT functional repertoire, which in many taxa includes multiple aspects of vegetative development such as leaf structure (Shalit et al., 2009), meristem activity (Hsu et al., 2011), and stomatal function (Kinoshita et al., 2011). Another outstanding question is the origin of opposing functions in the FT and TFL lineages. The relationship of the limited number of known gymnosperm homologs cannot be resolved relative to the angiosperm FT and TFL lineages (Figure 2 and Figure A1 in Appendix). Although the gymnosperm FT/TFL genes posses the typical $85 Y$ residue of the FT lineage, they do not appear to be biochemically conserved with FT in Arabidopsis (Karlgren et al., 2011), which casts doubt on earlier speculation regarding the ancestral functions of the genes (Shalit et al., 2009). The complexity of these findings highlight the importance of working with diverse model systems even within closely related lineages, such as the many FT paralogs of the grasses whose functions are only beginning to be teased apart.

An important aspect of these expanded studies is the realization that $\mathrm{CO}$ homologs do not always control the activity of FT-like genes. This is the case for both photoperiod sensitive and day neutral taxa (e.g., Pisum, Ipomoea, Solanum, Figure 5). Aside from Arabidopsis and rice, the studies in Populus represent the only other potential evidence of a $C O$ homolog regulating an FT homolog. Even with this example, however, the supporting data are limited to correlated expression patterns and the FT homolog (PtFT2) showing photoperiod response controls bud set, not flowering. Given that genes containing CCT domains are often involved in processes related to photoperiod and circadian rhythms (Figure 3; Putterill et al., 1995; Strayer et al., 2000; Yan et al., 2004; Cheng and Wang, 2005; Nakamichi et al., 2005; Datta et al., 2006; Xue et al., 2008; Serrano et al., 2009), we must consider the possibility that

\section{REFERENCES}

Ben-Naim, O., Eshed, R., Parnis, A., Teper-Bamnolker, P., Shalit, A., Coupland, G., Samach, A., and Lifschitz, E. (2006). The CCAAT binding factor can mediate interactions between CONSTANS-like proteins and DNA. Plant J. 46, 462-476.

Blackman, B. K., Strasburg, J. L., Raduski, A. R., Michaels, S. D., and Rieseberg, L. H. (2010). The role of recently derived FT paralogs in sunflower domestication. Curr. Biol. 20, 629-635.

Bohlenius, H., Huang, T., CharbonnelCampaa, L., Brunner, A. M., Jansson, S., Strauss, S. H., and Nilsson, O. (2006). CO/FT regulatory module controls timing of flowering and

CO homologs were independently recruited in Arabidopsis and rice to modulate homologs of FT. It is interesting to note that within Arabidopsis, two very closely related CO homologs, COL1 and COL2 (Figure 4), do not regulate FT (Ledger et al., 2001). Therefore, even considering just the Arabidopsis CO homologs, the most parsimonious reconstruction of the ancestral $C O$ lineage function would not necessarily be promotion of flowering in response to photoperiod. Research on how $\mathrm{CO}$ homologs function in a broader sample of angiosperm taxa, including further studies to build our understanding of $H d 1$ function in rice and the function of $\mathrm{CO}$ homologs in day neutral species, will help clarify the evolution of function among $\mathrm{CO}$-like genes and determine if they do in fact have a conserved role in flowering or are simply good candidates for co-option into developmental programs that come under photoperiod control.

Understanding the genetic pathways controlling flowering time in a number of species with different life histories that have adapted to different environments can provide valuable information about how this trait has evolved to accommodate the tremendous phenological variability present in plant taxa. While taking the candidate gene approach is a good first step to studying flowering time in diverse species, interpretation of data from such experiments requires a rich context of evidence from other clades of plants. The data from Arabidopsis and rice provide excellent starting points for studies on the genetic control of flowering time, however, making conclusions about the conservation of such a complex program without carefully considering evolutionary history can lead to oversimplifications. Although conservation is often the de facto hypothesis in evolution, discovering that multiple evolutionary lineages have independently evolved convergent developmental mechanisms that respond to similar environmental pressures allows us to appreciate the real power of evolution.

\section{ACKNOWLEDGMENTS}

We would like to thank Dr. Sarah Mathews, Dr. Charles Davis, and members of the Kramer Lab for critically reading and providing suggested improvements for this chapter and Dr. Amanda Brothers for suggestions on improving figures.

chloroplast genomes. J. Mol. Evol.58, 424-441.

seasonal growth cessation in trees. Science 312, 1040-1043.

Bradley, D., Carpenter, R., Copsey, L., Vincent, C., Rothstein, S., and Coen, E. (1996). Control of inflorescence architecture in Antirrhinum. Nature 379, 791-797.

Bradley, D., Ratcliffe, O., Vincent, C., Carpenter, R., and Coen, E. (1997). Inflorescence commitment and architecture in Arabidopsis. Science 275 , 80-83.

Chailakhyan, M. K. (1937). New facts in support of the hormonal theory of plant development. Dokl. Acad. Sci. U.S.S.R. 13, 79-83.

Chaw, S. M., Chang, C. C., Chen, H. L., and Li, W. H. (2004). Dating the monocot-dicot divergence and the origin of core eudicots using whole
Cheng, X. F., and Wang, Z. Y. (2005). Overexpression of COL9, a CONSTANS-LIKE gene, delays flowering by reducing expression of $\mathrm{CO}$ and FT in Arabidopsis thaliana. Plant J. 43, 758-768.

Chia, T. Y. P., Muller, A., Jung, C., and Mutasa-Gottgens, E. S. (2008). Sugar beet contains a large CONSTANS-LIKE gene family including a CO homologue that is independent of the early-bolting (B) gene locus. J. Exp. Bot. 59, 2735-2748.

Corbesier, L., Vincent, C., Jang, S. H., Fornara, F., Fan, Q. Z., Searle, I., Giakountis, A., Farrona, S., Gissot, L., Turnbull, C., and Coupland, G.
(2007). FT protein movement contributes to long-distance signaling in floral induction of Arabidopsis. Science 316, 1030-1033.

Cunningham, C. W., Omland, K. E., and Oakley, T. H. (1998). Reconstructing ancestral character states: a critical reappraisal. Trends Ecol. Evol. (Amst.) 13, 361-366.

Danilevskaya, O. N., Meng, X., Hou, Z. L., Ananiev, E. V., and Simmons, C. R. (2008). A genomic and expression compendium of the expanded PEBP gene family from maize. Plant Physiol. 146, 250-264.

Datta, S., Hettiarachchi, G., Deng, X. W., and Holm, M. (2006). Arabidopsis CONSTANS-LIKE3 is a positive regulator of red light signaling and root growth. Plant Cell 18, 70-84. 
Doi, K., Izawa, T., Fuse, T., Yamanouchi, U., Kubo, T., Shimatani, Z., Yano, M., and Yoshimura, A. (2004). Ehd1, a Btype response regulator in rice, confers short-day promotion of flowering and controls FT-like gene expression independently of Hd1. Genes Dev. 18, 926-936.

Faure, S., Higgins, J., Turner, A., and Laurie, D. A. (2007). The FLOWERING LOCUS T-like gene family in barley (Hordeum vulgare). Genetics 176, 599-609.

Felsenstein, J. (2003). Inferring Phylogenies. Sunderland, MA: Sinauer Associates, Inc.

Force, A., Lynch, M., Pickett, F. B., Amores, A., Yan, Y.-L., and Postlethwait, J. (1999). Preservation of duplicate copies by complementary, degenerative mutations. Genetics 151, 1531-1545.

Granovsky, A. E., and Rosner, M. R. (2008). Raf kinase inhibitory protein: a signal transduction modulator and metastasis suppressor. Cell Res. 18, 452-457.

Griffiths, S., Dunford, R. P., Coupland, G., and Laurie, D. A. (2003). The evolution of CONSTANS-like gene families in barley, rice, and Arabidopsis. Plant Physiol. 131, 1855-1867.

Hanzawa, Y., Money, T., and Bradley, D. (2005). A single amino acid converts a repressor to an activator of flowering. Proc. Natl. Acad. Sci. U.S.A. 102, 7748-7753.

Hayama, R., Agashe, B., Luley, E., King, R., and Coupland, G. (2007). A circadian rhythm set by dusk determines the expression of FT homologs and the short-day photoperiodic flowering respons in Pharbitis. Plant Cell 19, 2988-3000.

Hayama, R., and Coupland, G. (2004). The molecular basis of diversity in the photoperiodic flowering responses of Arabidopsis and rice. Plant Physiol. 135, 677-684.

Hayama, R., Yokoi, S., Tamaki, S., Yano, M., and Shimamoto, K. (2003). Adaptation of photoperiodic control pathways produces short-day flowering in rice. Nature 422, 719-722.

Hecht, V., Foucher, F., Ferrandiz, C., Macknight, R., Navarro, C., Morin, J., Vardy, M. E., Ellis, N., Beltran, J. P., Rameau, C., and Weller, J. L. (2005). Conservation of Arabidopsis flowering genes in model legumes. Plant Physiol. 137, 1420-1434.

Hecht, V., Knowles, C. L., Schoor, J. K. V., Liew, L. C., Jones, S. E., Lambert, M. J. M., and Weller, J. L. (2007). Pea LATE BLOOMER1 is a GIGANTEA ortholog with roles in photoperiodic flowering, deetiolation, and transcriptional regulation of circadian clock gene homologs. Plant Physiol. 144, 648-661.

Hecht, V., Laurie, R. E., Vander Schoor, J. K., Ridge, S., Knowles, C. L., Liew, L. C., Sussmilch, F. C., Murfet, I. C., Macknight, R. C., and Weller, J. L. (2011). The pea GIGAS gene is a FLOWERING LOCUS $\mathrm{T}$ homolog necessary for graft-transmissible specification of flowering but not for responsiveness to photoperiod. Plant Cell 23, 147-161.

Hedman, H., Kallman, T., and Lagercrantz, U. (2009). Early evolution of the MFT-like gene family in plants. Plant Mol. Biol. 70, 359-369.

Hemming, M. N., Peacock, W. J., Dennis, E. S., and Trevaskis, B. (2008). Low-temperature and day length cues are integrated to regulate FLOWERING LOCUS T in barley. Plant Physiol. 147, 355-366.

Hillis, D. M., Moritz, C., and Mable, B. K. (1996). Molecular Systematics. Sunderland, MA: Sinauer Associates, Inc.

Hsu, C.-Y., Adams, J. P., Kim, H., No, K., Ma, C., Strauss, S. H., Drnevich, J., Vandervelde, L., Ellis, J. D., Rice, B. M., Wickett, N., Gunter, L. E., Tuskan, G. A., Brunner, A. M., Page, G. P., Barakat, A., Carlson, J. E., dePamphilis, C. W., Luthe, D. S., and Yuceer, C. (2011). FLOWERING LOCUS $\mathrm{T}$ duplication coordinates reproductive and vegetative growth in perennial poplar. Proc. Natl. Acad. Sci. U.S.A. 108, 10756-10761.

Imamura, S. (1967). "Photoperiodic induction and the floral stimulus," in Physiology of Flowering in Pharbitis nil, ed. S. Imamura (Tokyo: Japanese Society of Plant Physiologists), 15-28.

Izawa, T. (2007). Adaptation of flowering-time by natural and artificial selection in Arabidopsis and rice. J. Exp. Bot. 58, 3091-3097.

Izawa, T., Oikawa, T., Sugiyama, N., Tanisaka, T., Yano, M., and Shimamoto, K. (2002). Phytochrome mediates the external light signal to repress FT orthologs in photoperiodic flowering of rice. Genes Dev. 16, 2006-2020.

Jaeger, K. E., and Wigge, P. A. (2007). FT protein acts as a long-range signal in Arabidopsis. Curr. Biol. 17, 1050-1054.

Kardailsky, I., Shukla, V. K., Ahn, J. H., Dagenais, N., Christensen, S. K., Nguyen, J. T., Chory, J., Harrison, M. J., and Weigel, D. (1999). Activation tagging of the floral inducer FT. Science 286, 1962-1965.

Karlgren, A., Gyllenstrand, N., Källman, T., Sundström, J. F., Moore, D., Lascoux, M., and Lagercrantz, U. (2011). Evolution of the PEBP gene family in plants: functional diversification in seed plant evolution. Plant Physiol. 156, 1967-1977.

Khanna, R., Kronmiller, B., Maszle, D. R., Coupland, G., Holm, M., Mizuno, T., and Wu, S.-H. (2009). The Arabidopsis B-box zinc finger family. Plant Cell 21, 3416-3420.

Kim, D. H., Doyle, M. R., Sung, S., and Amasino, R. M. (2009). Vernalization: winter and the timing of flowering in plants. Annu. Rev. Cell Dev. Biol. 25, 277-299.

Kim, S. J., Moon, J., Lee, I., Maeng, J. and Kim, S. R. (2003). Molecular cloning and expression analysis of a CONSTANS homologue, PnCOL1, from Pharbitis nil. J. Exp. Bot. 54, 1879-1887.

Kinoshita, T., Ono, N., Hayashi, Y., Morimoto, S., Nakamura, S., Soda, M., Kato, Y., Ohnishi, M., Nakano, T., Inoue, S., and Shimazaki, K. (2011). FLOWERING LOCUS $\mathrm{T}$ regulates stomatal opening. Curr. Biol. 21, 1232-1238.

Kobayashi, Y., Kaya, H., Goto, K., Iwabuchi, M., and Araki, T. (1999). A pair of related genes with antagonistic roles in mediating flowering signals. Science 286, 1960-1962.

Koch, M. A., and Kiefer, C. (2006). Molecules and migration: biogeographical studies in cruciferous plants. Plant Syst. Evol. 259, 121-142.

Kojima, S., Takahashi, Y., Kobayashi, Y., Monna, L., Sasaki, T., Araki, T. and Yano, M. (2002). Hd3a, a rice ortholog of the Arabidopsis FT gene, promotes transition to flowering downstream of Hd 1 under short-day conditions. Plant Cell Physiol. 43, 1096-1105.

Komiya, R., Ikegami, A., Tamaki, S. Yokoi, S., and Shimamoto, K. (2008). Hd3a and RFT1 are essential for flowering in rice. Development 135, 767-774.

Ledger, S., Strayer, C., Ashton, F., Kay, S. A., and Putterill, J. (2001). Analysis of the function of two circadianregulated CONSTANS-LIKE genes. Plant J. 26, 14-22.

Lifschitz, E., Eviatar, T., Rozman, A., Shalit, A., Goldshmidt, A., Amsellem, Z., Alvarez, J. P., and Eshed, Y. (2006). The tomato FT ortholog triggers systemic signals that regulate growth and flowering and substitute for diverse environmental stimuli. Proc. Natl. Acad. Sci. U.S.A. 103, 6398-6403.

Lin, M. K., Belanger, H., Lee, Y. J., Varkonyi-Gasic, E., Taoka, K. I., Miura, E., Xoconostle-Cazares, B., Gendler, K., Jorgensene, R. A., Phinney, B., Lough, T. J., and Lucas, W. J. (2007). FLOWERING LOCUS T protein may act as the long-distance florigenic signal in the cucurbits. Plant Cell 19, 1488-1506.
Liu, J., Yu, J., McIntosh, L., Kende, H., and Zeevaart, J. A. D. (2001). Isolation of a CONSTANS ortholog from Pharbitis nil and its role in flowering. Plant Physiol. 125, 1821-1830.

Magallón, S., and Sanderson, M. J. (2005). Angiosperm divergence times: the effects of genes, codon positions, and time constraints. Evolution 59, 1653-1670.

Martinez-Garcia, J. F., Virgos-Soler, A., and Prat, S. (2002). Control of photoperiod-regulated tuberization in potato by the Arabidopsis flowering-time gene CONSTANS. Proc. Natl. Acad. Sci. U.S.A. 99, 15211-15216.

Meng, X., Muszynski, M. G., and Danilevskya, O. N. (2011). The FTlike ZCN8 gene functions as a floral activator and is involved in photoperiod sensitivity in maize. Plant Cell 23, 942-960.

Michaels, S. D., Himelblau, E., Kim, S. Y., Schomburg, F. M., and Amasino, R. M. (2005). Integration of flowering signals in winter-annual Arabidopsis. Plant Physiol. 137, 149-156.

Miller, T. A., Muslin, E. H., and Dorweiler, J. E. (2008). A maize CONSTANS-like gene, conzl, exhibits distinct diurnal expression patterns in varied photoperiods. Planta 227, 1377-1388.

Nakamichi, N., Kita, M., Ito, S., Yamashino, T., and Mizuno, T. (2005). PSEUDO-RESPONSE REGULATORS, PRR9, PRR7 and PRR5, together play essential roles close to the circadian clock of Arabidopsis thaliana. Plant Cell Physiol. 46, 686-698.

Nakamura, S., Abe, F., Kawahigashi, H., Nakazono, K., Tagiri, A., Matsumoto, T., Utsugi, T., Ogamwa, T., Handa, H., Ishisa, H., Mori, M., Kawaura, K., Ogihara, Y., and Miura, H. (2011). A wheat homolog of MOTHER OF FT AND TFL1 acts in the regulation of germination. Plant Cell 23, 3215-3229.

Nemoto, Y., Kisaka, M., Fuse, T., Yano, M., and Ogihara, Y. (2003). Characterization and functional analysis of three wheat genes with homology to the CONSTANS flowering time gene in transgenic rice. Plant J. 36, 82-93.

Ohno, S. (1970). Evolution by Gene Duplication. Berlin: Springer-Verlag.

Page, R. D. M. (1998). Molecular Evolution: A Phylogenetic Approach. Oxford: Blackwell Science Ltd.

Pin, P. A., Benlloch, R., Bonnet, D., Wremerth-Weich, E., Kraft, T., Gielen, J. J. L., and Nilsson, O. (2010). An antagonistic pair of FT homologs mediates the control of flowering time in sugar beet. Science 330, 1397-1400. 
Pnueli, L., Carmel-Goren, L., Hareven, D., Gutfinger, T., Alvarez, J., Ganal, M., Zamir, D., and Lifschitz, E. (1998). The SELF-PRUNING gene of tomato regulates vegetative to reproductive switching of sympodial meristems and is the ortholog of CEN and TFL1. Development 125, 1979-1989.

Putterill, J., Laurie, R., and Macknight, R. (2004). It's time to flower: the genetic control of flowering time. Bioessays 26, 363-373.

Putterill, J., Robson, F., Lee, K., Simon, R., and Coupland, G. (1995). The CONSTANS gene of Arabidopsis promotes flowering and encodes a protein showing similarities to zinc finger transcription factors. Cell 80 , 847-857.

Serrano, G., Herrera-Palau, R., Romero, J. M., Serrano, A., Coupland, G., and Valverde, F. (2009). Chlamydomonas CONSTANS and the evolution of plant photoperiodic signaling. Curr. Biol. 19, 359-368.

Shalit, A., Rozman, A., Goldshmidt, A., Alvarez, J. P., Bowman, J. L., Eshed, Y., and Lifschitz, E. (2009). The flowering hormone florigen functions as a general systemic regulator of growth and termination. Proc. Natl. Acad. Sci. U.S.A. 106, 8392-8397.

Stamatakis, A. (2006). RAxML-VIHPC: maximum likelihood based phylogenetic analyses with thousands of taxa and mixed models. Bioinformatics 22, 2688-2690.

Strayer, C., Oyama, T., Schultz, T. F., Raman, R., Somers, D. E., Mas, P., Panda, S., Kreps, J. A., and Kay, S. A. (2000). Cloning of the Arabidopsis clock cone TOC1, an autoregulatory response regulator homolog. Science 289, 768-771.

Suarez-Lopez, P., Wheatley, K., Robson, F., Onouchi, H., Valverde, F., and Coupland, G. (2001). CONSTANS mediates between the circadian clock and the control of flowering in Arabidopsis. Nature 410, 1116-1120.

Swofford, D. L., and Maddison, W. P. (1992). "Parsimony, characterstate reconstructions and evolutionary inference," in Systematics, Historical Ecology, and North American Freshwater Fishes, ed. R. L. Mayden (Stanford, CA: Stanford University Press), 186-223.

Takahashi, Y., Teshima, K. M., Yokoi, S., Innan, H., and Shimamoto, K. (2009). Variations in Hd1 proteins, Hd3a promoters, and Ehd1 expression levels contribute to diversity of flowering time in cultivated rice. Proc. Natl. Acad. Sci. U.S.A. 106, 4555-4560.

Tamaki, S., Matsuo, S., Wong, H. L., Yokoi, S., and Shimamoto, K. (2007). Hd3a protein is a mobile flowering signal in rice. Science 316, 1033-1036.

Theissen, G. (2002). Secret life of genes. Nature $415,741$.

Theissen, G. (2005). Birth, life and death of developmental control genes: new challenges for the homology concept. Theory Biosci. 124, 199-212.

Trevaskis, B., Hemming, M. N., Dennis, E. S., and Peacock, W. J. (2007). The molecular basis of vernalizationinduced flowering in cereals. Trends Plant Sci. 12, 352-357.

Trevaskis, B., Hemming, M. N., Peacock, W. J., and Dennis, E. S. (2006). HvVRN2 responds to daylength, whereas HvVRN1 is regulated by vernalization and developmental status. Plant Physiol. 140, 1397-1405.

True, J. R., and Haag, E. S. (2001). Developmental system drift and flexibility in evolutionary trajectories. Evol. Dev. 3, 109-119.

Turck, F., Fornara, F., and Coupland, G. (2008). Regulation and identity of florigen: FLOWERING LOCUS T moves center stage. Annu. Rev. Plant Biol. 59, 573-594.

Turner, A., Beales, J., Faure, S., Dunford, R. P., and Laurie, D. A. (2005). The pseudo-response regulator PpdH1 provides adaptation to photoperiod in barley. Science 310 , 1031-1034.

Valverde, F. (2011). CONSTANS and the evolutionary origin of photoperiodic timing of flowering. J. Exp. Bot. 62, 2453-2463.

Valverde, F., Mouradov, A., Soppe, W. Ravenscroft, D., Samach, A., and Coupland, G. (2004). Photoreceptor regulation of CONSTANS protein in photoperiodic flowering. Science 303, 1003-1006.

Vaughan, D. A., Morishima, H., and Kadowaki, K. (2003). Diversity in the Oryza genus. Curr. Opin. Plant Biol. 6, 139-146.

Wenkel, S., Turck, F., Singer, K., Gissot, L., Le Gourrierec, J., Samach, A., and Coupland, G. (2006). CONSTANS and the CCAAT box binding complex share a functionally important domain and interact to regulate flowering of Arabidopsis. Plant Cell 18, 2971-2984.

Xue, W. Y., Xing, Y. Z., Weng, X. Y. Zhao, Y., Tang, W. J., Wang, L., Zhou, H. J., Yu, S. B., Xu, C. G., Li, X. H., and Zhang, Q. F. (2008). Natural variation in Ghd7 is an important regulator of heading date and yield potential in rice. Nat. Genet. 40 , 761-767.

Yamaguchi, A., Kobayashi, Y., Goto, K., Abe, M., and Araki, T. (2005). TWIN SISTER OF FT (TSF) acts as a floral pathway integrator redundantly with FT. Plant Cell Physiol. 46, 1175-1189.

Yan, L., Fu, D., Li, C., Blechl, A., Tranquilli, G., Bonafede, M., Sanchez, A., Valarik, M., Yasuda, S., and Dubcovsky, J. (2006). The wheat and barley vernalization gene
VRN3 is an orthologue of FT. Proc. Natl. Acad. Sci. U.S.A. 103, 19581-19586.

Yan, L., Loukoianov, A., Blechl, A., Tranquilli, G., Ramakrishna, W. SanMiguel, P., Bennetzen, J. L. Echenique, V., and Dubcovsky, J. (2004). The wheat VRN2 gene is a flowering repressor downregulated by vernalization. Science 303, 1640-1644.

Yano, M., Katayose, Y., Ashikari, M., Yamanouchi, U., Monna, L., Fuse, T. Baba, T., Yamamoto, K., Umehara, Y., Nagamura, Y., and Sasaki, T. (2000). Hd1, a major photoperiod sensitivity quantitative trait locus in rice, is closely related to the Arabidopsis flowering time gene CONSTANS. Plant Cell 12, 2473-2483.

Conflict of Interest Statement: The authors declare that the research was conducted in the absence of any commercial or financial relationships that could be construed as a potential conflict of interest.

Received: 17 September 2011; paper pending published: 06 October 2011; accepted: 31 October 2011; published online: 16 November 2011.

Citation: Ballerini ES and Kramer EM (2011) In the light of evolution: a reevaluation of conservation in the CO-FT regulon and its role in photoperiodic regulation of flowering time. Front. Plant Sci. 2:81. doi: 10.3389/fpls.2011.00081

This article was submitted to Frontiers in Plant Evolution and Development, a specialty of Frontiers in Plant Science. Copyright () 2011 Ballerini and Kramer. This is an open-access article subject to a non-exclusive license between the authors and Frontiers Media SA, which permits use, distribution and reproduction in other forums, provided the original authors and source are credited and other Frontiers conditions are complied with. 


\section{APPENDIX}

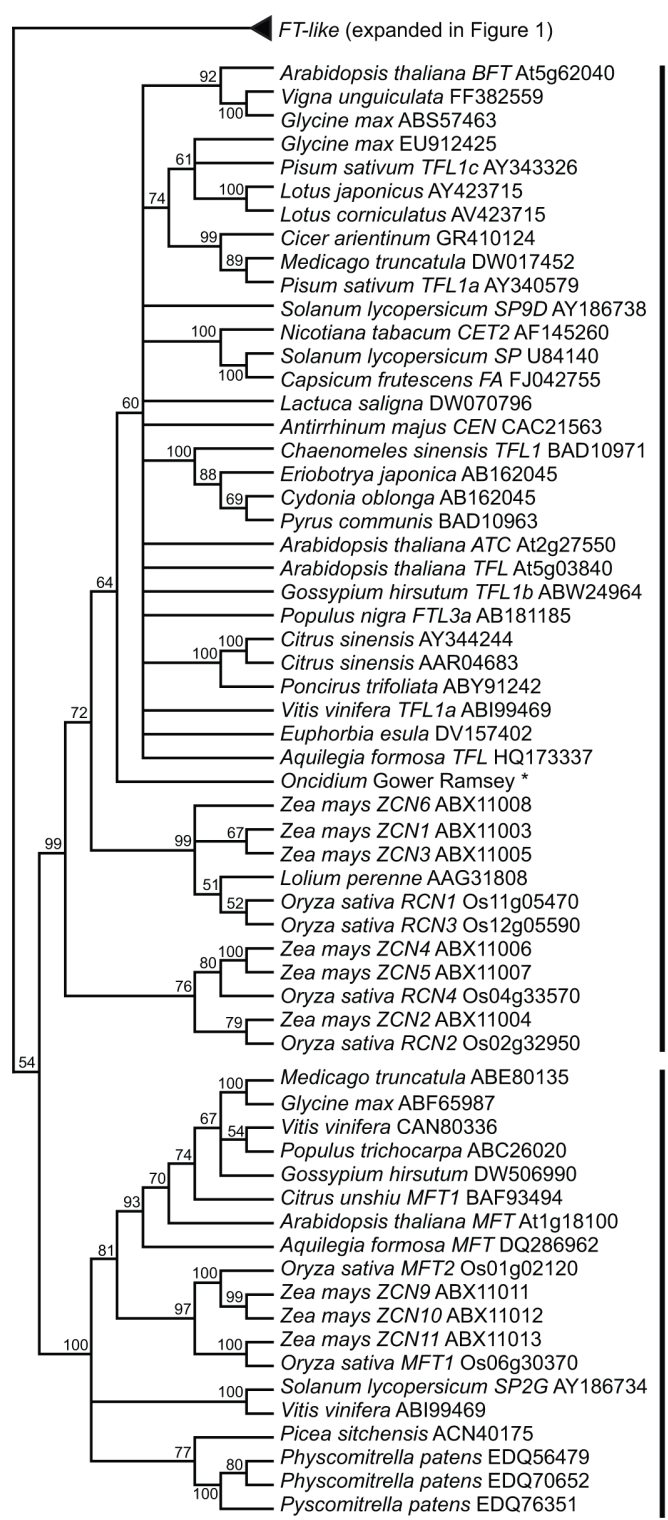

TFL-like

MFT-like

FIGURE A1 | Expansion of the PEBP gene tree to show TFL-like and MFT-like clades. Expansion of the tree presented in Figure 1. *Sequence for Oncidium Gower Ramsey was provided by C. H. Yang, National Chung Hsing University, Taichung, Taiwan, and does not have a GenBank accession number.

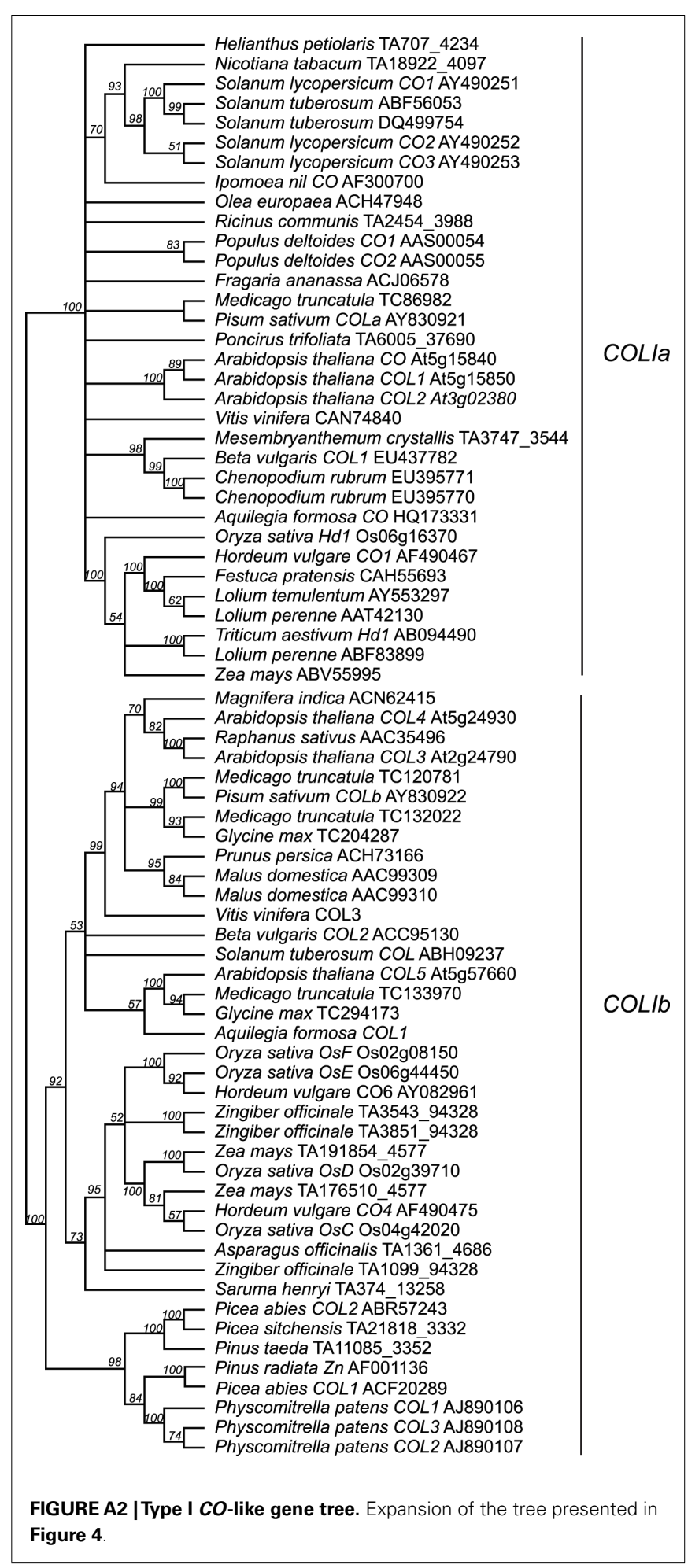

